\title{
DOS POESÍAS DE ALMANAQUE, POR LEOPOLDO ALAS
}

Noël M. VALIS

University of Michigan

La pasión por la poesía empieza pronto en la adolescencia de Leopoldo Alas, expresándose alternativamente en versos de índole espiritual o amorosa y versos de carácter satírico-burlesco. Ya tenemos síntomas de los impulsos poéticos de Alas en su periódico manuscrito juvenil Juan Ruiz, que va del 8 de marzo de 1868 al 14 de enero de 1869 e incluye 82 composiciones poéticas. En cartas íntimas a su gran amigo Pepe Quevedo va intercalando poesías reveladoras de una crisis mitad espiritual mitad sexual hacia los años 1876-77 (v. García Sarriá, Apéndice). Estudiosos de la obra clariniana como Marino Gómez Santos, José María Martínez Cachero, Jean-François Botrel y otros han exhumado poesías inéditas y otras olvidadas en revistas de provincias y de la capital como La Ilustración Gallega y Asturiana, Revista de Asturias, Ecos del Nalon, El Solfeo, La Gran Vía, Revista Contemporánea, etc. etc. Aunque siguen apareciendo poesías de Clarín en los años 90 e incluso póstumamente, parece que dejó de ser activo como poeta hacia 1880 o 1882 (Martínez Cachero 110) y sólo escribió esporádicamente a partir de esa fecha. Últimamente, Dionisio Gamallo Fierros y David Torres han publicado poesías que aparecieron el La Gran Vía (Madrid) en 1895: "Córdoba" (fechada 1882), "Fragmentos de un incendio" (de 1892) y "De la torre" (de 1893). Como Cervantes, Clarín no supo pulsar la lira en cuerdas de oro - en palabras suyas- pero sentía hondamente la poesía y lo expresaba magníficamente en su prosa, como han comentado Ricardo Gullón, Gonzalo Sobejano y otros. De ahí la importancia dada a estos versos de calidad discutible y el interés concedido a sus ideas sobre la poesía (v. por ejemplo, Gaos, Gallego Morell, González Ollé, Beser, Ezama Gil, Valis).

Con la verdadera explosión de publicaciones durante la Restauración, se hizo destacar por su gran abundancia el almanaque, del cual hay numerosos ejemplos en la Biblioteca Nacional. Botrel (XVII, n. 14) apunta de paso 
que Clarín colaboró en el Almanaque de "El Solfeo" para 1876 (Madrid, Imprenta de la Biblioteca Económica, 1875), con dos composiciones, "Juicio final de la temporada cómica de 1874 a 1875" (13-17) e "Historia de las malas letras" (49-55); y en el Almanaque diabólico para 1877 (Madrid, LIbrería de Anllo y Rodríguez, 1876), con Una "Revista del año cómico (1875 a 1876)" (33-35, 38-39, 42). No he podido ver el primer almanaque citado; en cambio, encontré junto con el Almanaque diabólico, otra publicación, $E l$ Huracán !! Almanaque para el año de 1877, editado por Antonio Sánchez Pérez (amigo de Alas) e ilustrado por Cubas (Madrid, Administración, 1876), en que aparece "Noche buena" de Clarín (128-129). Sin duda, de la pluma prolífica de Alas salieron más colaboraciones de este tipo, muy popular en su día; por ahora, reproduzco los versos al final de esta nota, como una pieza más del gran mosaico bibliográfico de la obra clariniana.

Como subgénero poético, "Revista del año cómico (1875 a 1876)" tiene sus antecedentes personales en Juan Ruiz, donde encontramos tres ejemplos, "Revista del medio año" (122-26), otra "Revista del medio año" (445-48) y "Juicio del año 1869" (449-52). El modelo profesional provenía de dos publicaciones satíricas de Madrid, El Cascabel y Gil Blas, a las que el joven Alas también mandaba versos (Martín-Gamero, Introducción a Juan Ruiz 20; y Martínez Cachero 106). Después, Clarín iba a perfeccionar su mordacidad brillante en las páginas de El Solfeo (y bajo otro título, La Unión), periódico de oposición democrática, donde el primer solo va a aparecer el 11 de abril de 1875 (Botrel XV). Y el mismo Almanaque diabólico para 1877 es producto de los redactores del Solfeo.

La crítica teatral, tema de esta revista, va a ser una preocupación constante durante casi toda la carrera literaria de Clarín. Recientemente, por ejemplo, Adolfo Sotelo ha documentado este fervor regeneracionista clariniano en el campo dramático, desenterrando dos artículos olvidados de 1899. La "revista del año cómico" debe leerse junto con la crítica en prosa que estaba escribiendo Alas al mismo tiempo. Artículos como "Teatros. ¡Aquí , a real, todo a real!"' (El Solfeo, №. 216, 5 de abril de 1876; en Preludios 59-62) y "Ateneo. La decadencia del teatro y la protección del gobierno" (El Solfeo, № 222, 11 de abril de 1876; en Preludios 62-64), nos dan una idea más amplia y más coherente del reformismo teatral de Alas que si leyéramos solamente piezas ligeras como la "Revista del año cómico". No obstante, en el fondo dicha revista encierra una crítica muy dura y seria contra la decadencia del teatro español. Al empezar el poema con una referencia épico-burlesca _-"Pericles a su siglo dejó nombre..."- se subraya la enorme distancia entre la época de Pericles (o la de Augusto, de Napoleón) y la edad presente,... la de Pina. Pina Domínguez se enriquecía tanto haciendo arreglos de obras francesas que se decía de él: "Y hasta Pina tiene coche / traducido del francés" (Baroja 785). La falta de valores literarios auténticos en el teatro queda clarísima aquí y en la última estrofa, cuando Clarín dice con cierta amargura: "...de libertad nos falta la voz santa, / ella sola es potente, / que donde no se piensa no se siente / y donde no se siente no se 
canta". Para Alas no cabe duda: el bajón teatral es síntoma de la estrangulación ideológica global que parecía caracterizar el período de la Restauración. La malicia cómica no quita la actitud de disidente en el joven Clarín.

Al pasar al segundo poema reproducido en estas páginas entramos en otro universo poético, uno que se relaciona íntimamente con la crisis espiritual y amorosa revelada en las cartas a José Quevedo en 1876-77. Como ser verá, "Noche buena" en realidad consta de tres poesías distintas, agrupadas bajo una sola rúbrica. La primera contiene la única alusión al título. Entre ésta y la segunda, "Como la nieve", existe un nexo temático, el de la mujer infiel y moralmente corrupta. En el último poema, "El mentir de las estrellas", se desarrolla mediante una estructura paralelística e interrogativa el tema del tormento espiritual. La forma misma de pregunta y respuesta acentúa la incertidumbre del poeta, quien concluye con estos versos: "- ¿QQué ves en las estrellas Y [el hombre impío] responde: / -iSarcasmos del engima!" He aquí tres ejemplos de la temática amorosa y espiritual que desde la adolescencia le preocupaba a Clarín. Es evidente que los tres poemas no poseen suficiente unidad de contenido y estilo entre sí, pero prevalece un tono de desilusión cínica tan fuerte que hasta cierto punto contrabalancea la falta de cohesión poética. La influencia combinada de Heine y Bécquer parece patente en el disgusto doloroso de la voz poética frente a las mentiras morales (la traición sexual) y espirituales (la traición metafísica). Pero ante todo, lo que se destaca en todos estos poemas es la postura altamente crítica de un joven escritor que todavía no sabe o no quiere perdonar las insuficiencias de su tiempo. 


\section{Revista del año cómico (1875 a 1876)}

Pericles a su siglo dejó nombre dándole el suyo que llenó la fama; cada siglo se llama como se llama un hombre.

Napoleón, Augusto

dieron nombre a su siglo, como es justo, y el año que termina

-que vale por un siglo a no dudarlotenemos que llamarlo como se llame Pina'; que si vivió el teatro, fue a su costa. ¡Viva el año de Pina y la langosta! Con Pina nos asedia el Español; y luego la Comedia. Yo, lector, te confieso que ya me tiene obseso esa Pina, que siempre está de parto. (No estoy obseso, lo que estoy es harto).

Mas no digo con esto, Dios me libre, que sea Escrich un Pérez de calibre ${ }^{2}$; y si Pina Domínguez no se queja Pérez Escrich le sirva de pareja.

Hiciéronse muy malas traducciones vertidas del francés al fregadero, usando un español y unas pasiones que no admite la tierra del puchero. El mismo Navarrete, el bien vestido, (porque Asmodeo es mote, no apellido), del francés nos tradujo en fácil español, cosa de lujo, un pleito que llamó de Sandoval ${ }^{3}$;

1. Mariano Pina Domínguez (1840-95), autor dramático prolífico, conocido por sus adaptaciones de obras extranjeras; según Botrel, entre 1875 y 1880 Pina "escribió, arregló o tradujo nada menos que unas 30 obras" (235).

2. Enrique Pérez Escrich (1829-97), novelista por entregas de gran popularidad, también estrenó el 25 de septiembre de 1875 la poco afortunada obra dramática El maestro de hacer comedias, en el Teatro Apolo.

3. Ramón Navarrete y Fernández Landa (1820-97), mejor conocido por su pseudónimo "Asmodeo", cronista de sociedad de La Epoca, había presentado durante la temporada un arreglo llamado El pleito de Sandoval. Es posible que sea una adaptación libre de Les Diamants de la couronne, opéra-comique de Eugenio Scribe, con música de Auber (1841), en que figura el personaje don Henrique de Sandoval. En 1854, Francisco Camprodón y Barbieri crearon la zarzuela Los diamantes de la corona, a base de la obra de Scribe. 
pleito digno del padre Nocedal ${ }^{4}$.

Ahora paso a tratar de originales;

Pérez Escrich se presentó el primero, y a vuelta de los celos de Morales ${ }^{5}$ que olían a madera de tintero - con estas formas castas Lope de Vega designó las astascompuso el señor Pérez susodicho una especie de drama de capricho; y porque el nudo desatar no pudo un cornudo trocó por... un cornudo. ¡Cómo son inflexibles esas leyes que rigen a los hombres y a los bueyes!

Ya de las Musas sin buscar la pista se presentó Gaspar con los Pasivos ${ }^{6}$, cada vez más realista siempre hablando de cuentas y recibos y letras a la vista, con otros mil recursos cotizables pero irrepresentables.

Yo le digo a ese autor, aunque le duela, que la culpa del mal no está en la escuela: el realismo es tal cual, pero siempre fue malo escribir mal.

Arrancar no es posible a Echegaray el lauro inmarcesible; ¿quién osará tocar a esa corona en cruda lid ganada si la lleva En el puño de la espada ${ }^{7}$ y esa espada, la fama lo pregona,

4. Cándido Nocedal (1821-85), director de El Siglo Futuro, político y escritor neocatólico. Ya era el blanco de la sátira clariniana en 1869. V. "El Manifiesto de Nocedal (Traducción libre)" en Juan Ruiz, 466-68.

5. Ricardo Morales, primer actor y futuro empresario y director del Teatro Apolo.

6. Enrique Gaspar (1842-1902), autor de Los pasivos, comedia estrenada en el Teatro del Circo el 15 de octubre de 1875, interpretada por Rafael Calvo y Victoriano Tamayo. Fue un estreno poco afortunado, según Daniel Poyán Díaz, en Enrique Gaspar. Medio siglo de teatro español. I, Madrid, Gredos, 1957, 58.

7. José Echegaray (1832-1916), cuya obra dramática En el puño de la espada fue un triunfo apoteósico al estrenarse el 12 de octubre de 1875, en el Teatro Apolo. Clarín siempre mostró mucha afición por el neorromanticismo de Echegaray. En 1891 el dramaturgo puso un prólogo a la 4 edición de Solos de Clarín. 
por el poder del genio fue templada?

Mas dijo quisquillosa la censura

(que da noventa y nueve en la herradura):

"me parece muy mal

lo de escribir con sangre en un puñal".

!Oh sublime criterio

que por eso no más se escandaliza

y tal censura le dirige, en serio,

al que sabe escribir en la ceniza!

\section{Compuso Campoamor}

un drama sobre cierta Blancafor ${ }^{8}$;

hizo Elisa Boldún ${ }^{9}$ muy bien la dama,

mucho mejor que D. Ramón el drama.

Yo al poeta venero,

pero la voz de la conciencia sigo,

y cuando ronca Homero

con la mayor franqueza se lo digo.

Sobre el asunto de la base oncena

habló un santo en la escena;

orador de cabildo

el tal Hermenegildo ${ }^{10}$,

sin llegar a decir cosa con cosa

nos predicó un sermón en verso-prosa

pero no, ¡vive Dios!,

que fue más de un sermón y más de dos.

El peor de los males

- a parte del tratar con animales-

es que la obrita parecióle buena

al gran D. Peregrín García Cadena ${ }^{11}$.

8. Ramón de Campoamor (1817-1901), autor de las Doloras, Humoradas y Pequeños poemas, tuvo menos éxito con sus ensayos teatrales. Clarín se refiere al estreno del drama iAsí se escribe la historia! en el Teatro del Circo el 23 de septiembre de 1875; el personaje principal es Albaflor ("Blancaflor" en el poema clariniano). Sólo se representó dos veces. V. la reseña de Alas, "Palique", El Solfeo, № 55 (25 de octubre de 1875), reprod. en Preludios 28-30.

9. Elisa Boldún (1847-1915); vino al Teatro Circo en 1874.

10. Hermenegildo, de Francisco Sánchez de Castro (1847-89), estrenado el 16 de noviembre de 1875, fue uno de los dramas "godos"; el otro es Theudis (1878), criticado en Solos de Clarín (1881). Alas satiriz6 Hermenegildo en "Aleluyas dramáticas", El Solfeo, № 84 (23 de noviembre de 1875), reprod. en Preludios 33-34. El "asunto de la base oncena" de Hermenegildo puede que sea una alusión maliciosa a una obra dramática de Enrique Gaspar, El onceno no estorbar, estrenada en 1860 y reeditada en 1876.

11 Peregrín García Cadena (1823-? ) fue crítico de teatros en El Imparcial y La Ilustración Española y Americana. Alas le satiriza en "Echegaray en provincias" El Solfeo, N" 479 ( 9 de febrero de 1877), reprod. en Preludios 104-06. 
Líbreme Dios, amén

de cuantas obras le parezcan bien.

Consumieron las damas mucha tila con la llegada del feroz Atila, pues es para asustar el héroe de Gaspar ${ }^{12}$.

Mas al fin sucedió, como otras veces, que fue mayor el ruido que las nueces: el bárbaro mostróse comedido y casi bien vestido; más que azote de Dios era un pacato, vamos, un mentecato;

y aunque bárbaro, hablaba el español mejor que un literato de la Puerta del Sol.

Retes y ... ya se sabe, Echevarría ${ }^{13}$ juntos en contubernio literario trajeron al de Urbino al escenario si con acierto no, con osadía.

Aplaudieron la claque y los amigos, tocó la prensa el bombo de la fama... ¡Saben los cielos, y serán testigos, lo malo que era el drama!

Ved la duda cruel en que me abismo, oh mellizos autores, ¿cuál la culpa tendrá de los errores de vuestro comunismo?

Sí, ¿cuál es el peor? ¿o sois lo mismo y sois los dos peores?

Un señor algo viejo y con muchos más años que consejo hizo en arte mayor un alegato sobre el asesinato de Julio César ${ }^{14}$, causa ya anticuada como aquella de Prim tan abultada. Los autores del crimen son habidos

12. Se refiere al drama de Enrique Gaspar llamado Atila, estrenado el 23 de diciembre de 1875 en el Teatro del Circo.

13. Francisco Luis de Retes (1822-1901), autor dramático, colaboró frecuentemente con Francisco Pérez Echevarría (1842-84). Se refiere a su obra La Fornarina, representada el 7 de enero de 1876.

14. Se refiere a La muerte del César, original de José María Díaz, estrenado el 19 de febrero de 1876 en el Teatro Apolo, con éxito mediano. 
allá entre bastidores

y resulta que son unos actores

tan malos como poco conocidos.

El teatro de Apolo

después de aquella muerte

cerró las puertas y quedóse solo:

castigo justo que le dio la suerte.

Y... ¿para qué seguir? No me interesa

decir lo mala que es La Marsellesa ${ }^{15}$,

ni tengo humor ni espacio

para hablaros de bodas en palacio ${ }^{16}$

ni de otras fruslerías

que vimos estrenar todos los días;

sólo juzgo oportuno

reservar un aplauso cariñoso

para Rienzi el Tribuno,

brillante ensayo de una señorita $\left(^{*}\right)^{17}$

liberal, inspirada y muy bonita.

¿Y qué mas? Nada más, triste la escena

arrastra, como todo, una cadena,

de libertad nos falta la voz santa,

ella sola es potente,

que donde no se piensa no se siente

y donde no se siente no se canta.

Talía y Melpómene en la agonía

yacen, todos los vimos,

el exterior oímos..

y en tanto el Ateneo discutía

si había decadencia o no la había... ${ }^{18}$

\section{Clarín}

(Almanaque diabólico para 1877, 1876, pp. 33-35, 38-39, 42)

(*) Advierto que la autora

fue señorita pero ya es señora. (N. del E.)

15. La Marsellesa, de Miguel Ramos Carrión (1845-1915), se estrenó el 1 de febrero de 1876 en el Teatro de la Zarzuela, con gran éxito.

16. Alusión a la obra, Una boda en palacio, por Francisco Pérez Echevarría y Gil Santibáñez, representada el 27 de enero de 1876, en el Teatro Español.

17. Rienzi el Tribuno, estrenado el 12 de enero de 1876 en el Teatro del Circo e interpretado por Rafael Calvo, fue obra de Rosario de Acuña (1851-1923), después casada con el comandante Rafael de la Iglesia. V. Luciano Castañon: "Aportación a la biografía de Acuña", Boletín del Instituto de Estudios Asturianos, Año 40, № 117 (1986), 151-71.

18. V. también el comentario de Alas en "Ateneo. La decadencia del teatro y la protección del gobierno". El Solfeo № 222 (11 de abril de 1876), reprod. en Preludios 62-64. 


\section{Noche Buena}

¡Noche buena! -hoy al salir de tu hogar y amor impío, acuérdate del dolor; ¡los pobres muertos de frío! ¡los pobres muertos de amor!

Como la nieve.

- "Como la nieve de la enhiesta cumbre, pura del cuerpo y alma,

ha de ser la mujer que llame esposa", un príncipe exclamaba.-

$Y$ un pajecillo que en la corte vive cuando el señor se casa, todas las noches a deshora besa

la mano de una dama...

como la nieve de la enhiesta cumbre, como la nieve blanca.

El mentir de las estrellas.

Al niño, que adormece en sus rodillas, le pregunta la madre:

${ }_{-}$¿Qué ves en las estrellas? y él responde: -Los ojos de los ángeles.

- ¿Qué ves en las estrellas? Grecia un día le preguntó a Pitágoras;

y el sabio respondió, como arrobado:

- iSon las celestes arpas!

Pregúntale Satán al cenobita en medio del desierto

- ¿Qué ves en las estrellas? y él responde: - iLas huellas del Eterno!

Y el ángel de la Guarda al hombre impío le dice entre sonrisas:

- ¿Qué ves en las estrellas? Y él responde: — ¿Sarcasmos del enigma!

\section{LeOPOLdo Alas}

(El Huracán!! Almanaque diabólico para el año de 1877 , 1876, pp. 128-29.) 


\section{BIBLIOGRAFÍA}

Alas, Leopoldo (Clarín). Juan Ruiz, Ed. Sofía Martín Gamero, Madrid, EspasaCalpe, 1985.

_- "Noche buena". En ElHuracán!! Almanaque para el año de 1877, ed. A [ntonio] Sánchez Pérez, Madrid, Administración, 1876, 128-29.

— Preludios de "Clarín”, ed. Jean François Botrel, Oviedo, IDEA, 1972.

"Revista del año cómico (1875 a 1876)". En Almanaque diabólico para 1877, Madrid, Librería de Anllo y Rodríguez, 1876. 33-35, 38-39, 42.

Baroja, Pío. Memorias. Obras completas. 7, Madrid, Biblioteca Nueva, 1949.

Beser, Sergio. Leopoldo Alas, crítico literario, Madrid, Gredos, 1968. 178 216.

Botrel, Jean-François. Introducción. Preludios de "Clarín", XIII-LXXIII.

Ezama Gil, Ángeles. "La crítica de la poesía en verso y un olvidado relato de Clarín", Boletín del Instituto de Estudios Asturianos, Año 42, № 128 (1988), 779-803.

Gallego Morell, Antonio. "Clarin". Poetas y algo más, Sevilla, Universidad de Sevilla, 1978. 50-55.

Gamallo Fierros, Dionisio. "El itinerario espiritual de Clarín”, La Voz de Asturias (Oviedo), 29 de noviembre de 1984, 20-21.

Gaos, Vicente. La poética de Campoamor. $2^{\mathrm{a}}$ ed. rev., Madrid, Gredos, 1969 , 140-61.

García Sarriá, Francisco. Clarín o la herejía amorosa, Madrid, Gredos, 1975.

Gómez Santos, Marino. "Clarín poeta (Dos composiciones en verso, inéditas, y una bibliografía)", Boletín del Instituto de Estudios Asturianos, Año 5 , $\mathrm{N}^{2} 14$ (1951), 396-401.

González Ollé, Fernando. "Del naturalismo al modernismo: los orígenes del poema en prosa y un desconocido artículo de Clarín", Revista de Literatura $\mathrm{N}^{\text {os. }}$ 49-50 (1967), 49-67.

"Prosa y verso en dos polémicas decimonónicas: Clarín contra Núñez de Arce y Campoamor contra Valera", Boletín de la Biblioteca de Menéndez Pelayo 39 (1963), 208-27.

Gullón, Ricardo. "Clarín, crítico literario", Universidad (Zaragoza) 26 (1949), 389-431. Reprod. en J.M. Martínez Cachero, ed. Leopoldo Alas "Clarín", Madrid, Taurus, 1978, 115-46.

Martínez Cachero, José María. "Los versos de Leopoldo Alas", Archivum 2 (1952), 89-111. Reprod. en J.M. Martínez Cachero, ed. Leopoldo Alas "Clarín", Madrid, Taurus, 1978, 105-11. (Se cita de este último). 
"Poesías inéditas de Clarín", La Lectura, Año 7, 2 (junio 1907), 162.

Sobejano, Gonzalo. "Poesía y prosa en La Regenta". En "Clarín " y su obra en el Centenario de "La Regenta", ed. Antonio Vilanova, Barcelona, Universidad, 1985 [1986], 293-316.

Sotelo, Adolfo. "Clarín y la crítica de teatros (Dos artículos desconocidos en Faro Moderno, 1899)", Segismundo $\mathrm{N}^{\text {os }}$ 43-44 (1986), 223-56.

Torres, David. "Tres poesías desconocidas de Leopoldo Alas". Boletín del Instituto de Estudios Asturianos, Año 40, № 117 (1986), 201-06.

Valis, Noël M. Leopoldo Alas (Clarín): An Annotated Bibliography, Londres, Grant \& Cutler, 1986. 